Autores: Andrea Durval da Silva, Cássia Regina S.L. Callegon,

Gabriela Nascimento de Azevedo Asaeda, Shirley Aparecida Lima e Wiviane Falasca Pereira

\title{
ADESÃO DA EQUIPE DE ENFERMAGEM AOS TREINAMENTOS PROMOVIDOS PELA EDUCAÇÃO CONTINUADA DO CENTRO DE REFERÊNCIA DE ÁLCOOL, TABACO E OUTRAS DROGAS
}

\author{
Educação em Saúde
}

Introdução:

O Centro de Referência de Álcool, Tabaco e Outras Drogas (CRATOD), realiza parceria com a Associação Paulista para o Desenvolvimento da Medicina (SPDM) e, considerando as constantes atualizações técnicas científicas e as capacitações periódicas da equipe pelo serviço de educação continuada é relevante manter a qualidade do serviço prestado de um modelo bem sucedido de cuidados para usuários de drogas em situação de vulnerabilidade extrema visto a importância da atuação da educação continuada na enfermagem.

\section{OBJETIVO}

Verificar a adesão da equipe de enfermagem aos treinamentos aplicados no CRATOD e sua relevância para a qualidade do serviço prestado.

\section{MÉTODO}

Trata-se de estudo exploratório, retrospectivo, de campo com abordagem de natureza quanti-qualitativa, através de dados coletados das listas de presença no período de novembro/2017 até novembro/2018, em 12 treinamentos/mês, realizados para o público alvo de 85 profissionais que compõem a equipe de enfermagem.

\section{RESULTADO}

Observou-se que nos meses de novembro e dezembro de 2017 ocorreu uma menor aderência por parte dos colaboradores de $29 \%$, sendo que de janeiro a novembro de 2018 obtivemos um aumento significativo nas médias de adesões dos profissionais da enfermagem em relação aos treinamentos, devido a intervenção da Educação Continuada, portanto este aumento significa que no primeiro semestre atingimos $58 \%$ de média de aderência e no segundo semestre $78 \%$.

\section{Adesão ao Treinamento - Gráfico 1}

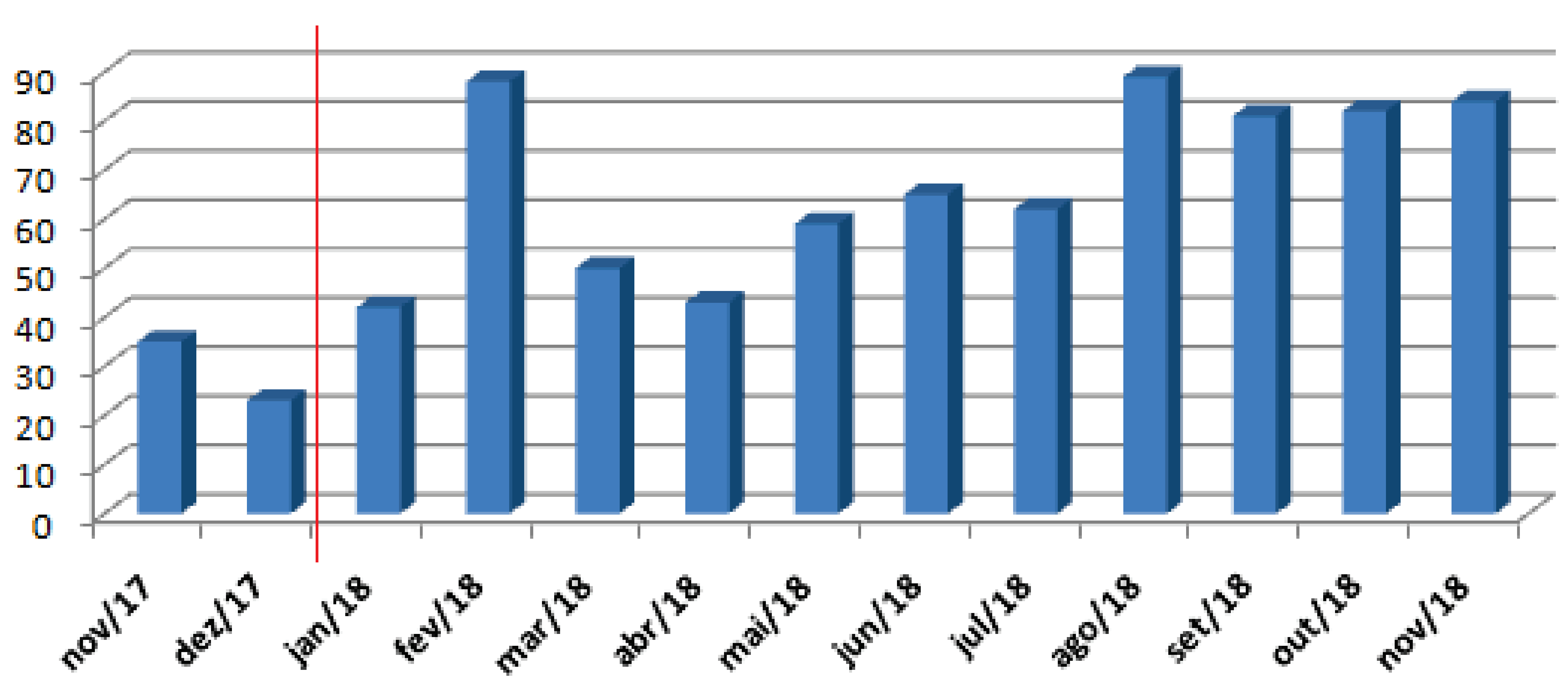

\section{Adesão ao Treinamento - Gráfico 2}

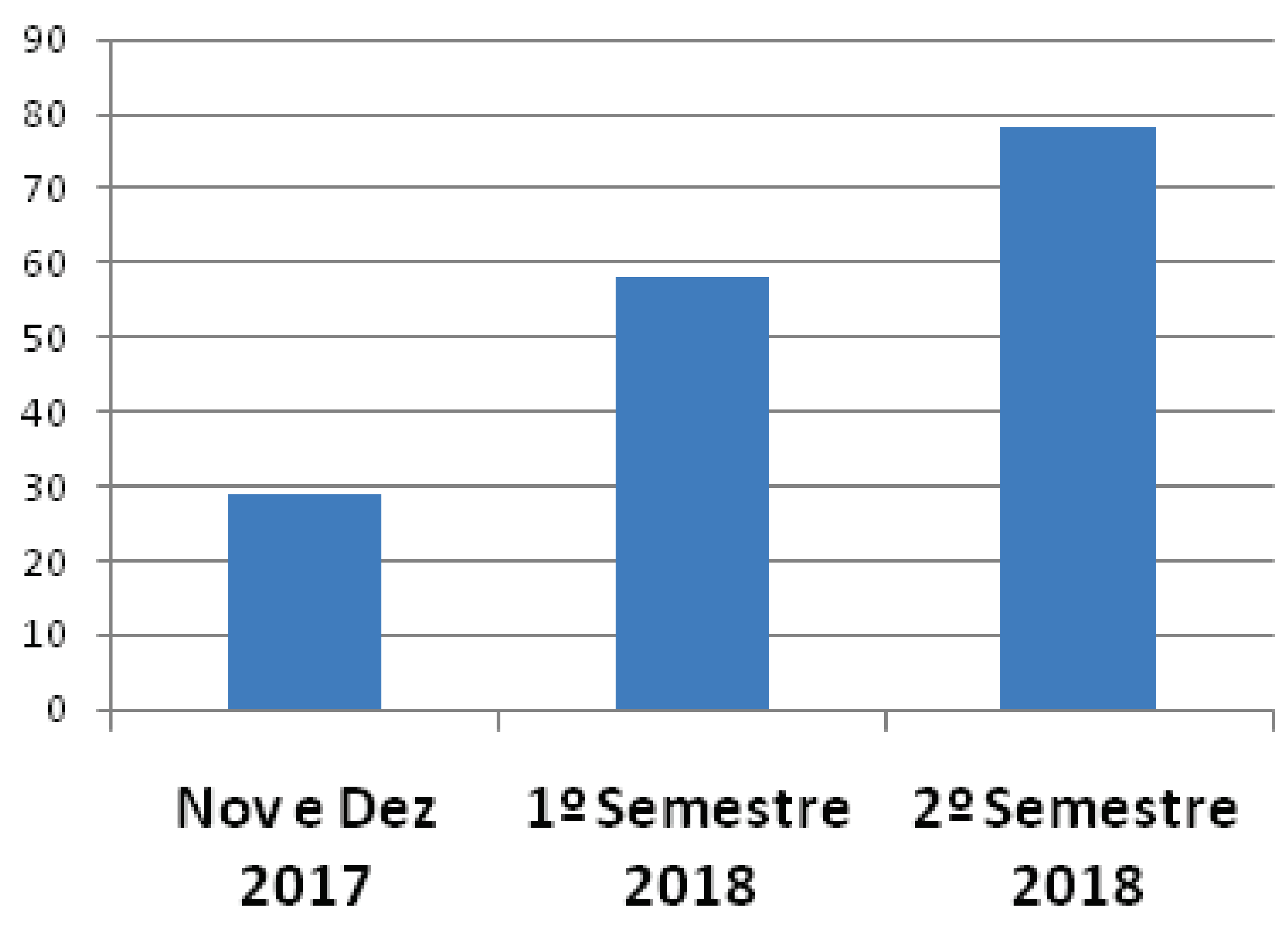

\section{CONCLUSÃO}

A Educação Continuada é uma ferramenta importante para a gestão, pois permite a identificação de possíveis falhas ou duvidas, durante os temas abordados e, desta forma, pode-se incentivar e promover a atuação na unidade, atendendo as demandas dos profissionais e as necessidades da instituição, visando a melhoria na qualidade da assistência. 